\title{
Ant diversity at Sunut forest, Khartoum, Sudan
}

\author{
Reeham Magboul"; Awatif Khider and Eihab Idris \\ Department of Zoology, Faculty of Science, University of Khartoum. P.O. Box 321, \\ Postal Code 11115, Khartoum, Sudan. \\ * Corresponding author: E-mail: reeham12@hotmail.com
}

\begin{abstract}
Due to their scientific value as bioindicators, assessment of ant diversity is an important target of biological diversity research, especially in regions where conservation threats are substantial. In this paper, we present a preliminary investigation of the ant fauna at Sunut forest which is a natural forest located in the middle of Khartoum city, the capital of Sudan. Due to its location, the habitat at Sunut forest is increasingly threatened by human activities. Our goal is to provide a database to serve as a guide for future management and conservation research taking place at this forest. During the study period (May, June and July 2012), ten species of ants were collected and classified. The ant collection contained species with different habitat preferences, indicating that the environment at Sunut forest is highly heterogeneous.
\end{abstract}

Keywords: Biodiversity; bioindicators; environmental monitoring; habitat disturbance; Ant community; Formicidae

\section{INTRODUCTION}

Biological indicators are species whose existence, physiology, behaviour or population dynamics reflect certain biotic or abiotic aspects of the environment and thus they can be used to monitor the state of ecological system through time (McGeoch, 1998). Bioindicators include a wide variety of species such as lichens, insects, copepods and microbial organisms and are used to monitor both terrestrial and aquatic environments. In conservation biology, bioindicators were proved to be a useful tool in monitoring and detecting changes in natural ecosystems, such as those caused by pollution and habitat disturbance (Rainio \& Niemelä, 2003). Moreover, indicator species can also be used to monitor the ecosystem recovery following environmental rehabilitation projects (Majer, 1983). In biodiversity studies, surveying indicator species represent a simple, cost-effective method to estimate the species richness in the community (Colwell \& Coddington, 1994).

Invertebrate communities represent robust indicators of the health of terrestrial environments. This is so because of their dominant biomass, extensive diversity in addition to their fundamental importance in the ecosystem function (Andersen, 1997). In particular, ants are used extensively as bioindicators, as their community composition and their response to habitat disturbance are both well-characterized (Andersen \& Majer, 2004). In an analysis of various insect groups as potential bioindicators, ants scored highest (Brown, 1997). Changes in ant community structure following disturbance have been found to reflect changes in many other invertebrate communities, indicating the high sensitivity of this group to habitat change and their representation of other components in the ecosystem (Majer, 1983; Andersen, 1997).

Al-Sunut is a natural forest that borders the White Nile at the Mogran area, Khartoum. It is a poor savannah habitat that is seasonally submerged following the 
Nile flooding and thus considered as an inland wet land ecosystem (Altayeb \& Hamed, 2003). The plant cover at the forest is dominated by Acacia nilotica trees. Sunut forest is characterized by rich biological diversity, as shown by previous surveys of avifauna and invertebrate fauna. Due to its location in the centre of a the crowded, urban region of Khartoum, Sunut forest is subjected to extensive human influence from various sources, including construction, agricultural and recreational activities taking place in the forest and its vicinity (Altayeb et al., 2013; Salah \& Idris, 2013). As a consequence, the forest has become the focus of attention for many Sudanese conservationists and environmentalists.

Few studies have been conducted on the ant fauna of Sudan. As a consequence, a substantial amount of data on the diversity, the structure and the population dynamics of ant communities in Sudan should be accumulated prior to any realistic attempt to incorporate ants as bioindicators in a local conservation or rehabilitation project. Ant diversity in Khartoum state has been previously surveyed by A. Khider (Unpublished data) who found twenty five species. In the present study, we investigate the species richness of the ant community at a particular location within Khartoum state, that is, the Sunut forest.

\section{MATERIALS AND METHODS}

\section{Collection site}

This study was carried out at the Sunut Forest $\left(15^{\circ} 35^{\prime} \mathrm{N}, 32^{\circ} 30^{\prime} \mathrm{E}\right)$. The site is bordered by the new White Nile Bridge from the North, the industrial area from the South, the Ghaba Street from the East and the White Nile from the West. A long the river bank there is a narrow cultivated area extending between the forest and the river bank.

\section{Collection of specimens}

Ant specimens were collected manually using a paintbrush moistened with $5 \%$ formalin or by using fine forceps. The collected specimens were dropped and preserved in glass tubes containing $7 \%$ formalin. Collection was performed during the daytime between 9 a.m. and 5 p.m. Following collection, the specimens were examined under the microscope.

\section{Identification of ant specimens}

Taxonomic categorization of collected ant specimens was performed following the key of Bolton (1994).

\section{RESULTS AND DISCUSSION}

\section{Classification of ant species recorded at Sunut forest}

Ten different species of ants (Family: Formicidae) have been identified in the current survey:

1- Pachycondyla sennaarensis (Mayr 1862)

2- Camponotus maculatus (Fabricius 1781)

3- Cataglyphis desertorum (Forel 1894)

4- Lepisiota gracilicornis (Forel 1892)

5- Paratrechina longicornis (Latreille 1802)

6- Monomorium bicolor (Emery 1877)

7- Monomorium areniphilum (Santschi 1911)

8- Crematogaster mimosae (Santschi 1914)

9- Cardiocondyla emeryi (Forel 1881)

10- Cardiocondyla elegans (Emery 1869) 


\section{The ant community at Sunut forest}

The marked feature of Sunut forest is that it shows extreme environmental heterogeneity. The area is divided into two distinct habitats: the inner, eastern part that is densely vegetated with Acacia nilotica and the outer, western part that borders the White Nile. A long the White Nile river bank there is a band of agricultural areas surrounding the forest from the west. In addition, even the inner part of the forest is heavily influenced by the recreational activities taking place both at the forest and at the bordering river bank. Moreover, the Sunut forest is impeded within the semidesert background that covers the entire Northern Sudan. As a consequence, the area provides a complex mixture of environmental conditions that is expected to attract species with variable habitat preferences. Supporting this prediction, the ant community at Sunut forest contains species associated with semi-desert conditions, with river bank conditions, with agriculture and with human habitation in addition to those species that are attracted to the poor-savannah habitat of the inner, relatively wild part of the forest. An initial comparison of the ant species composition at Sunut forest and that of Khartoum state in general indicates that there seems to be no fundamental difference in the community structure between the forest and its surroundings, since all the species recorded in the current survey have been observed elsewhere in Khartoum (A. Khider, unpublished data).

\section{Using ants as bioindicator at Sunut forest}

Due to the special status of Sunut forest as a hot spot of biological diversity in a crowded, rapidly growing capital, there is a need to conduct a regular monitoring program that investigates the temporal trends experienced by the fauna of Sunut forest, thus enabling the detection of potential environmental deterioration that might be caused by the increasing human impact. Ant community at Sunut forest could thus serve as a bioindicator that reflects the overall invertebrate diversity at the site and provides clues for potential habitat disturbance. Although the use of bioindicators is a simple and cost-effective approach to monitor the environmental condition, it requires the availability of substantial ecological data; this is why it is critical to understand the species diversity, the community structure and the population dynamics of ants in Sudan together with their characteristic response to habitat disturbance before ants can be used as an effective monitoring tool in conservation projects. We strongly recommend future research to accumulate this critical data through adopting more quantitative and comparative analysis than our study.

\section{REFERENCES}

Altayeb, A. M. and Hamed, D. M. (2003). Information Sheet on the Ramsar Wetlands (RIS).

Andersen, A. N. (1997). Using ants as bioindicators: multi-scale issues in ant community ecology. Conservation Ecology 1: 8.

Andersen, A. N. and Majer, J. D. (2004). Ants show the way Down Under: invertebrates as bioindicators in land management. Frontiers in Ecology and the Environment 2: 291-298

Bolton, B. (1994). Identification guide to the ant genera of the world. Harvard University Press, Cambridge.

Brown. K. S. (1997). Diversity, disturbance, and sustainable use of Neotropical forests: insects as indicators for conservation monitoring. Journal of Insect Conservation 1: 25-42. 
Colwell R. K. and Coddington J. A. (1994). Estimating terrestrial biodiversity through extrapolation. Philosophical Transactions of the Royal Society of London Series 345 (B): 101-118.

Eltayeb, H., Idris, E., Adam, A. Ezaldeen, T. and Hamed, D. (2012). A forest in a city: Biodiversity at Sunut forest, Khartoum, Sudan. The Egyptian Academic Journal of Biological Sciences Zoology 4: 199-209.

Majer, J. D. (1983). Ants: bio-indicators of minesite rehabilitation, land-use, and land conservation. Environmental management 7: 375-383.

McGeoch, M. (1998). The selection, testing and application of terrestrial insects as bioindicators. Biological Reviews 73: 181-201.

Osman, S. and Idris, E. (2013). A note on the bird diversity at two sites in Khartoum, Sudan. The Egyptian Academic Journal of Biological Sciences Zoology, 5:1-10.

Rainio, J. and Niemelä, J. (2003). Ground beetles (Coleoptera: Carabidae) as bioindicators. Biodiversity \& Conservation 12: 487-506.

\section{ARABIC SUMMARY}

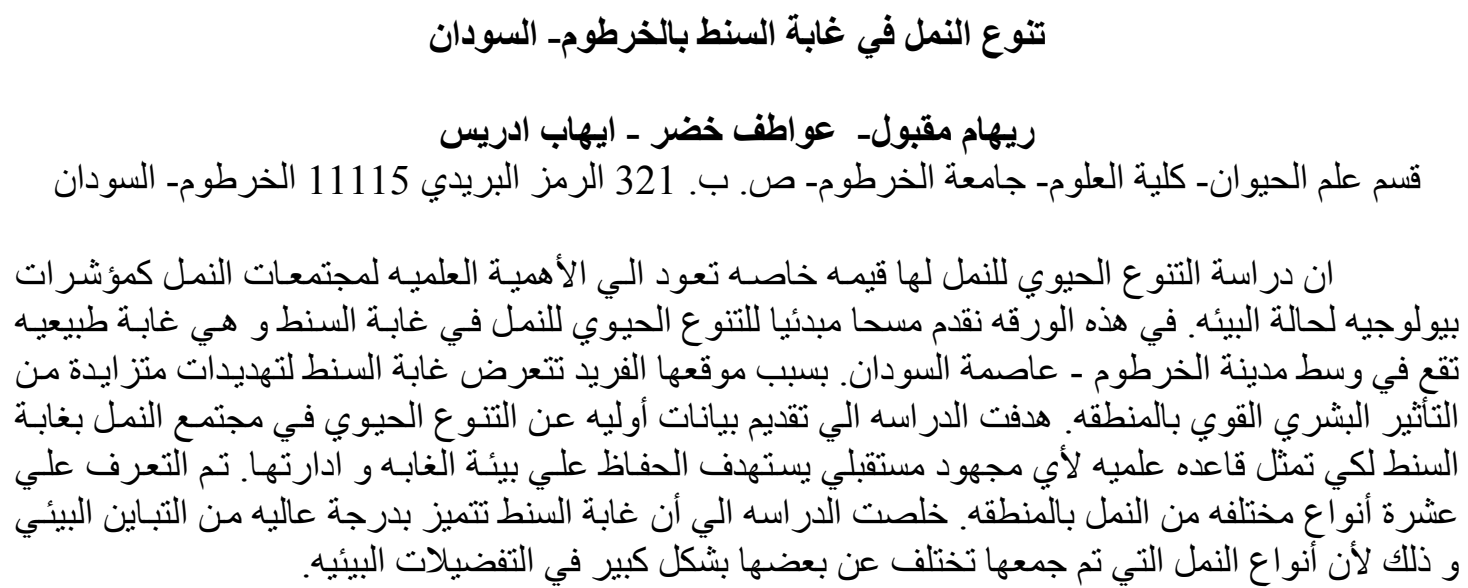

